\title{
EFFECTIVENESS IN HUMANS OF AN ANTIVIRAL DRUG BASED ON CHOLINERGIC AGONISTS WITH SPECIFIC DESIGN AND ROUTE OF ADMINISTRATION AGAINST COVID-19 SYMPTOMS IN A GROUP OF INFECTED PATIENTS VS. CONTROL GROUP
}

orlando Angulo ${ }^{1}$, Hector Fabio Restrepo ${ }^{2}$, José Gabriel León Higuera, Mario Leon Garcia, Fernando Mendive $^{3}$, matteo politi ${ }^{4}$

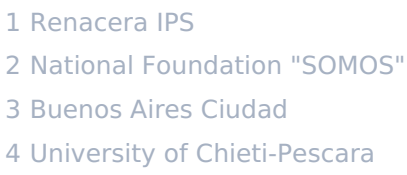

Funding: The author(s) received no specific funding for this work.

Potential competing interests: The author(s) declared that no potential competing interests exist.

\section{Abstract}

\section{Objective}

To establish the therapeutic action of a nicotinic cholinergic agonist agent composition in synergy with other non-cholinergic molecules (CA) in the COVID-19 symptoms in a group of human patients infected with SARS-CoV-2 vs. control group.

Methods

Randomized open-label trial pilot study where 80 patients were randomly assigned to receive standard of care $(\mathrm{SOC})$ treatment as outpatient treatment after PCR+ test; SOC plus CA was administered in the intervention group (40 patients). SOC was administered in the control group (40 patients).

Basic Odds Ratio study (95\% confidence interval) in 40 patients for intervention group and 40 patients for the control group. The evaluation in the groups was carried out during 15 days assessing the improvement or worsening of each symptom daily.

Results:

Fever $(O R=0.897)$, Cough $(O R=0.571)$, Dyspnea $(O R=0.460)$, Muscle fatigue $(O R=0.250)$, Cephalea $(O R=0,570)$, Ageusia $(O R=0.150)$, Anosmia $(O R=0.650)$, General malaise $(O R=0.316)$, Nasal congestion $(\mathrm{OR}=0.890)$, are less than 1 converting the use of the cholinergic agent in a protective and therapeutic factor showing therefore improvement of these symptoms, after its use, compared to the control group.

\section{Conclusions:}

The positive results obtained on the symptoms caused by COVID-19 by delivering mixture of cholinergic agonists molecules and other non-cholinergic supportive molecules (CA) with special oral and nasal 
route of administration and specific pharmacological design against COVID-19 in humans infected by SARS-CoV-2 versus the control group is a (novel) promising therapeutic approach to fight SARS-COV-2. Larger multicentrical trials in humans are encouraged.

\section{EFFECTIVENESS IN HUMANS OF AN ANTIVIRAL DRUG BASED ON CHOLINERGIC AGONISTS WITH SPECIFIC} DESIGN AND ROUTE OF ADMINISTRATION AGAINST COVID-19 SYMPTOMS IN A GROUP OF INFECTED

\section{PATIENTS VS. CONTROL GROUP}

León Higuera J.G. ${ }^{1,2}$, Restrepo Guerrero F.H ${ }^{3}$, León García M. ${ }^{4}$, Politi M M ${ }^{5}$, Mendive F. ${ }^{6}$, Angulo OJ..$^{7,8,9}$ 1 Physician, specialist in sports medicine and physical rehabilitation, Head of the sports medicine department at the San José Children's University Hospital and at the San José University Hospital in Bogotá, Colombia

2 Assistant professor of the physical activity and sports medicine residency at the Health Sciences University Foundation, Colombia 3 Physician, Veterinarian, Epidemiologist, Assistant Professor Research Division at University Foundation of Health Sciences, Colombia, Research Director at National Foundation "SOMOS", Colombia 4 Physician, specialized in Pneumology by the by the Health Sciences University Foundation, Colombia, member of the Colombian Pneumological Foundation.

5 PhD in Chemistry and Technology of Bioactive Substances, Department of Pharmacy, University of Chieti-Pescara, Chieti Scalo, Italy

6 Biochemist. PhD in Molecular Biology, Doctor of the University of Buenos Aires, Specialist in Molecular Biology, Department of Genetics and Molecular Biology, College of Pharmacy and Biochemistry, Argentina 7 Physician by the Health Sciences University Foundation, specialist in sports medicine and physical rehabilitation, PHIV-AIDS primary care, Sports Medicine and Sports Nutrition Department, Renacerá IPS Villavicencio, Colombia 8 Clinical and Experimental Medicine research department Physician-in-chief, Renacerá IPS Villavicencio, Colombia 9 Professor and Researcher at Universidad Cooperativa de Colombia, Villavicencio Colombia

\section{HIGHLIGTHS:}

- A nicotinic hypothesis for SARS-CoV-2 has been proposed by several authors.

- An alternative interaction other than S/ACE2 that disrupts nicotinic receptors trough alternative epitopes or extracellular domains linked to nAChrs, a so-called TBS (toxin-binding site), has been reported.

- ACE2/S-SARS-CoV-2 RBD plays a key role in infectivity.

- TBS linked to nAChRs, involving a cholinergic epitope or cryptic epitope, may play a crucial role in severity and mortality observed in COVID-19 disease.

- This issue should be addressed and targeted urgently being cholinergic agonist molecules one of the 
best candidates for this purpose.

- A nicotinic cholinergic agonist composition has been tested in humans showing preliminary significant effectiveness for the improvement and reduction of the major symptoms of COVID-19 when compared to a control group.

\section{ABSTRACT}

\section{Objective}

To establish the therapeutic action of a nicotinic cholinergic agonist agent composition in synergy with other non-cholinergic molecules (CA) in the COVID-19 symptoms in a group of human patients infected with SARS-CoV-2 vs. control group.

\section{Methods}

Randomized open-label trial pilot study where 80 patients were randomly assigned to receive standard of care (SOC) treatment as outpatient treatment after PCR+ test; SOC plus CA was administered in the intervention group (40 patients). SOC was administered in the control group (40 patients).

Basic Odds Ratio study (95\% confidence interval) in 40 patients for intervention group and 40 patients for the control group. The evaluation in the groups was carried out during 15 days assessing the improvement or worsening of each symptom daily.

\section{Results:}

Fever $(O R=0.897)$, Cough $(O R=0.571)$, Dyspnea $(O R=0.460)$, Muscle fatigue $(O R=0.250)$, Cephalea (OR $=0,570)$, Ageusia $(O R=0.150)$, Anosmia $(O R=0.650)$, General malaise $(O R=0.316)$, Nasal congestion $(\mathrm{OR}=0.890)$, are less than 1 converting the use of the cholinergic agent in a protective and therapeutic factor showing therefore improvement of these symptoms, after its use, compared to the control group. Conclusions:

The positive results obtained on the symptoms caused by COVID-19 by delivering mixture of cholinergic agonists molecules and other non-cholinergic supportive molecules (CA) with special oral and nasal route of administration and specific pharmacological design against COVID-19 in humans infected by SARS-CoV2 versus the control group is a (novel) promising therapeutic approach to fight SARS-COV-2. Larger multicentrical trials in humans are encouraged. 


\section{ABBREVIATIONS}

Ach, Acetylcholine; ADAM17, ADAM metallopeptidase domain 17; ACEi, Angiotensin-converting enzyme inhibitors; ARBs, Angiotensin II receptor blockers; CA, Cholinergic Agent (mixed with supportive non cholinergic molecules); CNS, Central Nervous System; CS, Cholinergic System; CRS, Cytokine release syndrome; HLH, hemophagocytic Lymphohistiocytosis; IL-6, interleukin 6; IS, Immune System; LPS, lipopolysaccharides; NRT, Nicotine Replacement Therapy; nAChRs, Nicotinic acetylcholine receptors; NK, Nuclear factor; NF-Kb, Nuclear factor kappa beta; PRR, pattern recognition receptor; RAAS, ReninAngiotensin-Aldosterone System; SARS, Severe Acute Respiratory Syndrome; SOC, standard of care treatment; STAT, Signal Transducer and Activator of Transcription; RBD, receptor-binding domain; TBS, toxin-binding site; TNF $\alpha$, tumor necrosis factor alpha; TNFRI , TNF receptor-1; TNFRII , TNF receptor-2

\section{KEYWORDS}

Cholinergic agonists; Cholinergic system; Nicotine; Nicotinic acetylcholine receptors; nAChR;COVID-19; SARS-CoV-2; nAChR; Nicotinic hypothesis; Human trial; RAAS (Renin-Angiotensin-Aldosterone System); ACE2; Anti-inflammatory cholinergic pathway, Long Covid, Post-Covid Syndrome

\section{INTRODUCTION}

\subsection{THE NICOTINIC CHOLINERGIC HYPOTHESIS AND THE USE OF NICOTINIC CHOLINERGIC AGONISTS}

\section{AGAINST SARS-COV-2}

Clinical evidence from hospitals and researchers from several countries (2) (16) and data from the US CDC (5) including peer-reviewed studies found a lower prevalence of COVID-19 among smokers, which it could be attributed to a probable protective factor for nicotine contained in the cigarettes but not from cigarette or smoking itself.

A nicotinic hypothesis on SARS-COV-2/COVID-19 (2) (3) and on the probable effectiveness of cholinergic agonists in COVID-19 disease has been established (8) (11).

This hypothesis is based and sustained on clinical observations and on several peer-reviewed studies $(6,7)$, from the US CDC $(5)$, and systematic reviews $(8,9)$ meta-analysis $(9,10)$

L'Assistance Publique - Hôpitaux de Paris is testing in a large multicentrical-randomized study nicotinic drugs as cholinergic agonists against COVID-19 in the form of nicotine patches (12).

he present randomized open-label trial pilot study in humans has been carried out with a new drug that has recently been specifically designed against COVID-19 by the company Niccovid ${ }^{\circledR}$ and that has been preliminarily named Cholinergic Agent (CA).

Cholinergic agonist molecules such as nicotine used therapeutically do not have a toxicity and are well 
tolerated $(15,16)$ and safe even at long-term use $(17)$, they do not have relevant or minimal side effects, nor addiction potential or withdrawn symptoms when applied to non-smokers (16), even at high doses (18), nor significant cardiovascular risk (19-22) even in patients with previous cardiovascular and coronary events $(23,24)$ even with concomitant smoking $(25)$ when administered at appropriate therapeutic doses and posology and taking into account the risk-benefit ratio (26). Nicotine itself as a molecule, aside from the cigarette, does not exhibit carcinogenic properties (27) and its medicinally inhaled nasal application does not significantly alter lung function, nor diastolic blood pressure when compared with placebo (28).

In silico studies support the hypothesis that nicotine interacts positively in the disruption of SARS-CoV-2 on the human angiotensin-converting enzyme II (ACE2) $(29,30)$ and also in the dysregulation of the nicotiniccholinergic system by SARS-CoV-2 $(3,31)$.

\subsection{PATHOPHYSIOLOGY OF SARS-COV-2 AND THE ROLE OF THE POSSIBLE MECHANISM OF ACTION OF}

\section{NICOTINIC CHOLINERGIC AGONISTS IN COVID-19}

$\beta$-coronaviruses have the ability to enter the peripheral nerves and spread through the brainstem, affecting the respiratory and cardiovascular centers.

A cryptic epitope in the S1-SARS-CoV2 (aa 365-390) is not mutating and it is involved in the disruption with innate immune cells from ACE2 and $\alpha 7-n A C h R$ (36).

SARS-CoV-2 activates NF-KB (Nuclear factor kappa beta) (37) that controls immune and inflammatory responses through pattern recognition receptors (PPR) and accumulated Angll. Several studies indicate that cholinergic agonists such as nicotine inhibits the production of pro-inflammatory cytokines in macrophages by inhibiting NF-KB 8 that requires ubiquitination of IKB (38) through a modulatory mechanism dependent on the cholinergic system via $\alpha 7 n A C h R s$ (39).

The activation of $\alpha 7 n A C h R s$, deregulated by SARS-Cov-2, can prevent IkB degradation and p65 nuclear translocation in addition to modulating the signaling pathways of p38 kinase and nuclear factor-kB (40), which would explain why nicotinic cholinergic agonists have a therapeutic potential in monocytes, macrophages, and endothelial cells affected in COVID-19. All this induces the production of inflammatory cytokines such as TNF $\alpha$ and IL-6 by means of ADAM17 (Metalloprotease) (41) followed by the activation of IL6 AMP (Amplifier).

The ACE2 receptor is affected by SARS-CoV2 causing cytopathic damage and pyroptosis in cells that express this enzyme $(50,51)$. Once the binding and fusion with ACE2 is completed, the virus manages to internalize itself, raising angll levels and activating the angl receptor due to RAAS imbalance with the overexpression of ADAM17 and TNF $\alpha$, establishing a vicious inflammatory cycle. When the levels of expression of ACE2 and ADAM17 or their functions are altered, blood pressure can be affected in its regulation from the central nervous system, as well as the regulation of neuro-inflammatory processes (51). The nervous system and the immune system have an interface that involves the vagus nerve and the anti-inflammatory nicotinic pathway with acetylcholine and its nicotinic receptors (52).Vagus nerve and its function play a key role in preventing viral infections. Its hyperactivation through nAChR 
could regulate RAAS system helping in the SARS-CoV-2 ravages (53).

Activation of immune cells to produce pro-inflammatory cytokines is common in infections of viral origin. The vagus nerve and the CNS can be activated by these proinflammatory cytokines, affecting via afferent CNS processing centers such as the respiratory centers. In the efferent pathway, the body can activate the vagus nerve to fight inflammatory processes by inhibiting the overproduction of cytokines (54) in macrophages.

The role of ACh is not only a modulator of immune cells, but it is the main neurotransmitter of the vagus nerve and is in charge of the nervous regulation of the functions associated with homeostasis and organs. Some regulatory T lymphocytes can mimic the nervous system through the synthesis of ACh in order to mitigate or regulate an eventual overproduction of cytokines by macrophages. This ACh mechanism is carried out thanks to the specificity and efficiency of the $\alpha 7$ subunits of the nicotinic receptors, which are very important regulators in inflammatory processes $(55,56)$.

SARS-CoV-2 dysregulates ACE2 and $\alpha 7 n A C h R$ receptors in human macrophages (57) by increasing or promoting cytokine storm by hindering the regulatory role of the cholinergic anti-inflammatory pathway on the production of inflammatory cytokines.

Researchers found that a diminished cardiac vagal activity observed in patients with pulmonary and cardiometabolic disease could lead to death or critical illness and that an increase in the vagal tone can be a protective factor from a cytokine release syndrome (53). Active nicotine intake stimulates the cholinergic anti-inflammatory pathway, which is a protective factor in various infectious and inflammatory illnesses as e.g. ulcerative colitis $(58,59)$. This, despite the fact that smoking has a negative impact on health.

\subsection{NICOTINE AND SARS-COV-2}

Nicotine is an alkaloid found in various plants, especially in the Nicotiana sp. leaf, and it is only one of the 7,000 chemical components released by the burning industrial cigarette and therefore, a single molecule cannot be comparable to the cigarette in its entirety and nor is it the cause of the multiple ravages of smoking on human health. That is why it is necessary to highlight that the effects of nicotine in the body are always related to the dosage, the route of administration, and the chemical compounds with which it reacts $(60)$. The inhaled route with smoke inhalation is the most widespread in the world and represents many health risks due to all the chemical residues resulting from cigarette combustion. However, nicotine and other cholinergic agonists administered without the combustion pathway have other effects. An approach to nicotine and other direct nicotinic cholinergic molecules with added supportive noncholinergic molecules for antiviral, anti-inflammatory and immunomodulatory prophylactic and therapeutic purposes trough an intranasal and oral route of administration differs radically from the smoked route being potentially a valid option.

The nicotinic cholinergic system is one of the major modulators of the immune response and of the stress axis (hypothalamus - pituitary - adrenal). The endogenous ACh agonist (Acetylcholine) and the exogenous nicotine agonist for any $\mathrm{nAChR}$ open ion channels in the receptor, allowing cation flow and inducing a wide variety of biological responses. The acetylcholine receptor modulates the interactions between the nervous 
system and the immune system.

Pharmacological subunit clearance assays revealed that presynaptic nAchRs include the alpha 7 subunit and that nAChRs present in CNS enhance rapid excitatory transmission, revealing a likely mechanism for the CNS and behavioral effects of nicotine (62). For this reason, we propose a therapeutic and prophylactic route of nasal administration that mimics the entry route of the virus through the nasal mucosa to increase transmission and a rapid excitatory response with higher bioavailability and rapid arrival to the CNS, a phenomenon that is not seen with NRT products like chewing gums or transdermal patches.

Nicotine has a high power of action on the nAChRs of alveolar macrophages and on the central nAChRs of macrophages associated with the CNS and the bronchial tree. SARS-CoV-2 blocks the cholinergic system by dysregulation of nAChRs, inhibiting the nicotinic cholinergic anti-inflammatory pathway, triggering hemophagocytic Lymphohistiocytosis (HLH), viral sepsis, and lung damage (63). It can also infect terminal areas of the afferent or efferent fibers of the vagus nerve causing a down regulation of ACE2 producing local inflammation by interruption of the cholinergic pathway. Experimental studies indicate that direct stimulation of the efferent vagus nerve in response to endotoxin exposure in rodents had an inhibitory effect on TNF reducing both systemic inflammation and mortality (64).

The activity of the vagus nerve is clearly decreased by SARS-CoV-2 and is itself decreased in patients with obesity and diabetes, affecting the body's immunity and anti-inflammatory capacity (65). $\alpha 7 n A C h R$ are present in interstitial and alveolar macrophages in mices' lungs, having induced-obesity in mice an impact in the number of $\alpha 7 n A C h R$ cells in alveolar and interstitial macrophages that may affect the cholinergic anti-inflammatory pathway (66).

Computational modeling studies found that nicotine has a binding affinity at certain terminal amino acid residues in the binding site pocket of ACE2/SARS-CoV-2-S with antagonistic effect (29).

The alpha7nAChR subunit is abundant in alveolar macrophages, immune cells, nervous system and airway associated macrophages (67). An acute nicotinic effect mediated by receptors has been identified in alveolar macrophages with anti-inflammatory therapeutic potential in animal models, which is curiously reversed by alpha-bungarotoxin (68), a nAChR antagonist toxin which is also contained in the SARS-CoV-2 genomic sequence (2).

SARS-CoV-2 blocks ACh (Acetylcholine) by efferent pathways of the vagus nerve, affecting communication with macrophages and $\alpha 7 n A C h R$. This results in an inhibition of the cholinergic anti-inflammatory pathway

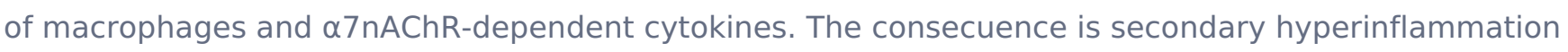
due to the inability to modulate TNF- $\alpha$ downwardly.

Modulation of ADAM17 (TNF- $\alpha$ converting enzyme) (69) by cholinergic agonists could have a beneficial and protective effect against COVID-19 (70). Additionally, nicotine and cholinergic agonists (71) have a regulatory effect on the RAAS axis.

\subsection{SARS-COV-2 AND NACHR SUBUNITS:}

Farsalinos et al. identified an interaction between aa381-386 of the SARS-CoV-2 glycoprotein S and aa189192 of the extracellular domain of the alpha9 subunit of nAChR, a region that forms the core of the "toxin 
binding site" from the nAChRs (57). The authors also identified an interaction very similar to the interaction between $\alpha 9$ nAChR and $\alpha$-bungarotoxin and a similar interaction was observed between $\alpha 7$ pentameric nAChR and SARS-CoV-2 glycoprotein S in addition to an interaction between the binding domain of ligands of a pentameric $\alpha 7$ of the nicotinic receptor and the S1 subunit of the SARS-CoV-2 glycoprotein S. Recent computational modulations (72) showed a clear interaction between SARS-CoV-2 and nAChR and the disruption in the anti-inflammatory response of the cholinergic system. This interaction between the alpha 7 subunits and the SARS-CoV-2 glycoprotein S1 was disrupted when cholinergic agonists and molecules such as Acetylcholine, Carbamylcholine, Cytisine, Epibatidine, Galantamine, Nicotine, Succinylcholine and Varenicline were docked.

\subsection{MECHANISM OF ACTION AND DESIGN OF ANTIVIRAL, ANTI-INFLAMMATORY AND IMMUNOMODULATORY}

\section{CHOLINERGIC AGONIST (CA) COMPOSITION AGAINST SARS-COV-2}

A composition called preliminary CA (Cholinergic Agent) has been developed by Niccovid ${ }^{\circledR}$ and contains 16 main active ingredients based on nicotine along with several other cholinergic and non-cholinergic molecules whose mechanism of action and pharmacodynamics is specifically designed to work in synergy against SARS-CoV-2 to prevention, treatment and probably also for the recovery of patients suffering from Post-Covid Syndrome.

The design of the CA drug is not only intended as an antiviral but also as an anti-inflammatory and immunomodulator. These qualities potentially give it a therapeutic effect against SARS-CoV-2 dangerous mutations and against current or new variants as well. If such new strains may appear, they should not $a$ priori outdate the mechanism of CA's therapeutic action.

The drug not only contains nicotine but also specific cholinergic agonist molecules that exhibit nicotine replacement properties and more specifically regulate $\alpha 9$ and $\alpha 7 \mathrm{nAChRs}$ and stimulate a wide variety of nicotinic acetylcholine receptors (nAChR), such as neuromuscular receptors ( $\alpha 12 \beta 1 \gamma \delta$ or $\alpha 12 \beta 1 \gamma \varepsilon$ ) and which are inhibited by the snake venom peptide $\alpha$-bungarotoxin. In addition, these other molecules may be more specific and effective than nicotine against cognitive disorders and neuroinflammation, problems observed in a large group of patients affected by COVID-19. Several of these molecules exhibit substitutive as well as synergistic properties with nicotine and its enhancing effects, a priori increasing its pharmacokinetic and therapeutic activity, acting as allosteric modulators in nAChRs.

On the other hand, other molecules of non-cholinergic origin were introduced into CA for modulating the oxidative stress of nicotine and do also have anti-inflammatory, antifungal, antioxidant, neuroprotective and gastroprotective properties (the enteric system is also affected by SARS-CoV-2), facilitating, some of them, the healthy regulation of glucose in diabetics. The mentioned supporting molecules for the cholinergic agonist molecules contained in CA would provide synergies and extra effectiveness through a differentiated pathway of the Renin-Angiotensin-Aldosterone axis by regulating the ACE enzyme and iron (serous ferritin values are overexpressed in many severe COVID-19 patients) in addition to having analgesic, antipyretic, chemopreventive, angiogenic, and antiemetic properties. The have also known 
properties against certain types of pulmonary fibrosis and exhibit antioxidants properties also, and they do mediate in the modulation of the NF-KB activation cascade.

Thus, the CA agent has a synergy of cholinergic agonists molecules together with non-cholinergic agonists added molecules that enhance trough complementary and alternative pathways CA's mixture properties for fighting COVID-19.

The CA composition has been designed to have specific anti-inflammatory properties through the effect of some of its molecules in the reduction of TNF- $\alpha$ levels in the brain, reduction of IL- 6 levels and in the prevention of STAT3 and NFKB phosphorylation induced by lipopolysaccharides (LPS) or TNF- $\alpha$ in SH-SY5Y, HEK293, human microglia, and human blood mononuclear cells.

Although the aforementioned nicotinic hypothesis proposed by several authors has been based exclusively on the study of the nicotine molecule against SARS-CoV-2, we believe that a drug with a mixture of several molecules with the described properties and by a combined administration of oral drops and especially of a nasal spray, would have a much greater effectiveness in the preventive and therapeutic management of COVID-19. The administration of CA in pulverized intranasal aerosol or nasal spray has been specifically designed to achieve an excitatory and therapeutic effect much faster and more directly on arrival at the CNS than other routes such as sublingual or transdermal. The intranasal liquid spray solution can reach the higher centers through the olfactory receptor neurons of the olfactory mucosa via the cribriform plate and the nerve endings of the olfactory bulb. Moreover, the nasal spray has the advantage of offering better absorption and higher bioavailability of cholinergic agonist molecules than patches or tablets and prevents the exhalation of viral particles or other particles unlike, for example, in the case of a theoretical nebulization administration with inhalation. Thus, the pharmacokinetic strategy of CA use is to provide a slow systemic effect by the oral route with the administration of oral drops in combination with a rapid neurotropic effect by nasal spray administration, adapting dosage according to the patient's profile and needs.

\section{METHODS}

\subsection{Ethics committee approval}

This study has been verified and evaluated by the Cediff Biomedical Research Ethics Committee, stating that the protocol complies with the ethical standards described in the national and international regulations related to biomedical research. The risk-benefit ratio was found favorable by the Ethics Committee for the subjects participating in the research, which is widely described in the justification of the study, protocol, and informed consent. This study has been endorsed by Ethics Committee guaranteeing its adherence to the following international standards related to biomedical research on human subjects: Nuremberg Code (International Tribunal of Nuremberg) 1947. Declaration of Helsinki. World Medical Association, 1964 and later revisions; Belmont Report, Report of the National Commission for the Protection of Human Subjects of Biomedical and Behavioral Research 1979; Universal Declaration on Bioethics and Human Rights, UNESCO 2005. Likewise, it adheres to the following national Colombian regulations: Resolution 8430 of 1993, Resolution 3823 of 1997, Resolution 2378 of 2008 and all the 
guidelines and updates issued by Colombian regulatory agency (INVIMA) or the Colombian Ministry of Health and Social Protection in relation to the subject.

\subsection{Study design}

The composition to be studied is made up of cholinergic agonist agents and other non-cholinergic agonist agents (CA) with synergistic interactions and with a specific route of administration.

CA has been patented (2 patents were applied under numbers \#2013130.6 and \#2013131.4 at Uk's Patent Office which form the basis for international protection) and its design, dosage and route of administration have been made specifically to combat COVID-19 in form of oral drops and nasal spray.

Group A: infected patients (40 patients): After a positive COVID-19 PCR test, patients receive SOC plus a daily dose of CA nasal spray (1 puff on each nostril every twelve hours) and oral drops (9 drops in $175 \mathrm{~mL}$ of water every 6 hours).

Group B: control patients (40 patients): a control group taking only SOC has been established also after a positive COVID-19 PCR test.

The same daily monitoring evaluation was done in both groups to assess the evolution of the disease based on scientifically supported medical scales for each symptom.

Ethnicity: the subjects were Colombian from white ethnicity ( $88 \%$ of Colombian population is white).

\section{Inclusion criteria:}

- positive patient for COVID-19 by PCR with results no more than 5 days old.

- outpatient under ambulatory care (non-hospitalized)

- Recruitment: patients were randomly recruited from a database of patients diagnosed with positive PCR tests for SARS-CoV-2 from several hospitals in Colombia.

\section{Exclusion criteria:}

- patient under in-ward hospital care, even if they have positive antigens and / or PCR.

- Decline in study participation.

- Under 18 years old.

\subsection{Data collection}

Group A received SOC + CA nasal spray and CA oral drops daily in the indicated dose according to the following criteria:

Clinical data: Date of suspected infection, date of onset of symptoms, date of PCR + or positive antigen for COVID-19, previous comorbidities (heart disease, kidney disease, lung disease, smokers $<10$ cigarettes / day, smokers > 10 cigarettes / Day, non-smokers, liver disease, pheochromocytoma, hyperthyroidism, hypertension, diabetes mellitus, drug dependence, other diseases.

Pharmacological data before COVID-19 infection. Following medications for ongoing comorbidities previously to COVID-19- were collected in both groups: ACEi, ARBs, Beta blockers, Salbutamol, Benzodiazepines, Antidepressants, Hydroxychloroquine, Heparin, Enoxaparin, Statins, INT-therapy, corticosteroids, NSAIDs, opiates, levothyroxine.

Pharmacological data prescribed as SOC for COVID-19: Following medications (SOC) for mitigating COVID- 
19 symptoms, that were prescribed by head physicians to the patients, were collected in both groups: Salbutamol, ASA, NSAIDs, Azithromycin, Nebulizers, Ivermectin, Enoxaparin, Heparin, Hydroxychloroquine, Corticosteroids, Oxygen therapy, Antihistamines, Anti-influenza drugs, Antipyretics, Antibiotic.

\subsection{The following symptoms and tolerance to CA measured:}

Symptoms:

- fever, cough, dyspnea, muscle fatigue, cephalea, ageusia, anosmia, chest pressure, general malaise, nasal congestion.

CA tolerance: side-effects and their time duration:

- Nasal itching, oropharyngeal discomfort, dizziness, nausea, headache, slight increase in heart rate, rhinorrhea, lacrimation, general malaise.

Measurements were made according to internationally accepted standard medical criteria and scales under the design of an expert in epidemiology.

Group B did receive SOC but did not receive CA and was used as an epidemiological control group to compare the efficacy of CA who have gone through the disease with some already existing treatment protocols as i.e. NSAIDs and/or ivermectin among others.

The evaluation in groups A \& B was carried out for 15 days assessing the improvement or worsening of each symptom on a daily basis, with day 0 being the day of measurement of symptoms without the administration of CA and taking days 1 to 14 the measurement of the evolution of each symptom with SOC + CA for group A and without CA but with SOC for group B.

\subsection{Analysis plan}

A basic OR study analysis was performed by analyzing the information collected with Microsoft SPSS software. Statistically significant tests were considered if the p-value was less than 0.05 (IC 95\%); as well as a concept of the tendency of some inconclusive outcome will be given.

\subsection{Methods and clinical scales for evaluation of each symptom}

1. Fever calculated in:

- - "Yes", I have a fever

- - "No", I don't have a fever

For statistical purposes we have converted "Yes"/"No" to "1"/"0" in order to calculate the following values: Day 0 (before starting treatment). CA treatment from Day 1 to Day 14

2. Dyspnea calculated from 0 to 4 according to the modified mMRC (Medical Research Council) scale, within the indirect scales, was initially used to study pneumoconiosis, but has since been modified to measure dyspnea. Of English origin, it has prognostic value. Previously, the MRC scale ranged from 1 to 5 , but now the ATS recommends a scale that is incorporated into the BODE and which mainly measures the magnitude of the task that causes the patient to experience shortness of breath. The grades are: 
- "0" Dyspnea occurs only with great physical effort

- "1" Dyspnea occurs when walking fast on the flat or when climbing a gentle slope

- "2" Dyspnea makes it impossible to keep up with other people of the same age

- "3" You have to stop and rest when walking 100 m or within a few minutes of walking on the flat

- "4" The dyspnea prevents the patient from leaving the house or appears with activities such as dressing or undressing

3. Headache (cephalea) calculated in:

- - "Yes", I have a headache

- - "No", I don't have a headache

For statistical purposes we have converted "Yes"/"No" to "1"/"0" in order to calculate the following values: Day 0 (before starting treatment). CA treatment from Day 1 to Day 14

4. Muscular fatigue calculated according to:

Muscle fatigue calculated from 0 to 10 according to Gunnar Borg's updated scale devised in the 1980s and improved a few years ago, a system for assessing intensity based not on value measurements but on the patient's own perception of effort. This is a fatigue scale that measures the perception of fatigue from 1 to 10, which was originally intended as a way of assessing medical damage, obtaining a standardized response to the sensations of pain, so different in each patient. In sports and, in particular, in exercise tests, the rating of perceived effort (RPE), measured by Borg's rating of the scale of perceived effort (RPE scale), is a quantitative measure of the frequent use of perceived effort during physical activity. In medicine, this is used to document the patient's exertion during a test, and sports coaches use the scale to assess training intensity and competition. This scale is especially used in the clinical diagnosis of choking and dyspnea, chest pain, angina, and musculoskeletal pain. The CR-10 scale is most appropriate when there is a predominant sensation arising from a specific area of the body, for example, muscle pain, quadriceps pain or fatigue or from lung responses.

The Borg scale can be compared with other linear scales such as the Likert scale or a visual analogue scale. The sensitivity and reproducibility of the results are generally very similar, although the Borg can exceed the Likert scale in some cases.

5. Cough calculated in:

- "Yes", I have a cough

- "No", I don't have a cough

For statistical purposes we have converted "Yes"/"No" to "1"/"0" in order to calculate the following values:

Day 0 (before starting treatment). CA treatment from Day 1 to Day 14

6. Ageusia calculated in:

- "Yes", I have ageusia

- "No", I don't have ageusia

The patient is asked about the sensation of taste and the flavors he feels with the food (sweet, spicy, salty, etc.). 
For statistical purposes we have converted the "Yes"/"No" to "1"/"0" in binary to calculate the following values:

Day 0 (before starting treatment). CA treatment from Day 1 to Day 14

7. Anosmia calculated in:

- "Yes", I have anosmia, I don't smell "Coffee" and/or "Vinegar"

- "No", I don't have anosmia, I smell correctly "Coffee" and/or "Vinegar"

The patient is asked about the sensation of smell and the smells he feels when smelling coffee and vinegar. The coffee and vinegar anosmia test used for COVID-19 patients in South Korea and other countries, such as by the Argentinean Ministry of Health, was used in this study.

For statistical purposes we have converted the "Yes"/"No" to "1"/"0" in binary to calculate the following values:

Day 0 (before starting treatment). CA treatment from Day 1 to Day 14

8. Chest tightness calculated in:

The patient is asked if he feels "tightness in the chest or thorax".

- "Yes", I have chest tightness

- "No", I don't have chest tightness

For statistical purposes we have converted "Yes"/"No" to "1"/"0" in order to calculate the following values:

Day 0 (before starting treatment). CA treatment from Day 1 to Day 14

9. General malaise:

There are several scales for measuring the intensity of "general malaise" which are normally calculated in a similar way to VAS from 0 to 10.

"General malaise" calculated in:

- 0, I have no general malaise

- to

- 10, maximum general malaise, extremely intense.

\section{Nasal congestion:}

The patient is asked if he feels "nasal congestion".

Nasal congestion calculated in:

- "Yes", I have nasal congestion

- "No", no nasal congestion

For statistical purposes we have converted "Yes"/"No" to "1"/"0" in order to calculate the following values:

Day 0 (before starting treatment). CA treatment from Day 1 to Day 14

\section{RESULTS}




\subsection{Descriptive statistics.}

Within the intervention group, $47.50 \%$ correspond to the male gender while $52.50 \%$ to the female gender, the mean age is 45,15 years with a standard deviation of 18.03634 years. For the control group, $67,50 \%$ corresponded to female gender with a mean age of 53.7 years and 32,50\% were male. SD was 13.13041 for group B.

Within the medical history, following diseases were present in the intervention A Group as follows: hypertension $27.5 \%$; diabetes mellitus $2.5 \%$, heart disease $0 \%$, kidney disease $2.5 \%$, lung disease $25.0 \%$, liver disease $2.5 \%$, pheochromocytoma $0.0 \%$, autoimmune thyroiditis $12.5 \%$, gastrointestinal disease $2.5 \%$, drug dependence $0.0 \%$, obesity $5.0 \%$, cancer $1 \%$.

Within the medical history, following diseases were present in the B control group as follows: hypertension $37.5 \%$; diabetes mellitus $0 \%$, heart disease $25.0 \%$, kidney disease $15.0 \%$, lung disease $12.5 \%$, liver disease $2.5 \%$, pheochromocytoma $0.0 \%$, autoimmune thyroiditis $12.5 \%$, gastrointestinal disease $5.0 \%$, drug dependence $0.0 \%$, obesity $5.0 \%$, cancer $1 \%$.

The number of smokers of $<10$ cigarettes / day and smokers $>10$ cigarettes / day was zero in the A group as well in the B control group (Colombia has a low prevalence of smokers of $7.0 \%$ according to official data) which avoids biases in the study for this specific case.

Regarding the previous use of medications, patients were told to not suspend any medication for their previous comorbidities nor the SOC treatments as NSAIDs or others that were prescribed for COVID-19 symptoms treatment by their physicians. This applies for both groups.

Following medications for ongoing comorbidities -previously to COVID-19- were reported in group A (intervention group): ACEi 15.0\%, ARB 5.0\%, Beta blockers 12.5\%, Salbutamol 2.5\%, Benzodiazepines $0.0 \%$, Antidepressants $0.0 \%$, Hydroxychloroquine $0.0 \%$, Heparin $0.0 \%$, Enoxaparin $2.5 \%$, Statins $10.0 \%$, INT-therapy $0.0 . \%$, corticosteroids $2.5 \%$, NSAIDs $0.0 . \%$, opiates $12.5 \%$, levothyroxine $5.0 \%$.

Following medications (SOC) for mitigating COVID-19 symptoms, that were prescribed by head physicians to the patients, were reported in group A: Salbutamol 5.0\%, ASA 17.5\%, NSAIDs 27.5\%, Azithromycin 10.0\%, Nebulizers $2.5 \%$, Ivermectin $17.5 \%$, Enoxaparin $0.0 \%$, Heparin $0.0 \%$, Hydroxychloroquine $0.0 \%$, Corticosteroids $10.0 \%$, Oxygen therapy $2.5 \%$, Antihistamines $12.5 \%$, Anti-influenza drugs $20.0 \%$, Antipyretics $17.5 \%$, Antibiotics $2.5 \%$.

Following medications for ongoing comorbidities -previously to COVID-19- were reported in group B (control group): ACEi 12.5\%, ARB 10.0\%, Beta blockers 0.0\%, Salbutamol 10.0\%, Benzodiazepines 0.0\%, Antidepressants $2.5 \%$, Hydroxychloroquine $0.0 \%$, Heparin $0.0 \%$, Enoxaparin $2.5 \%$, Statins 0.0\%, INTtherapy $0.0 . \%$, corticosteroids $2.5 \%$, NSAIDs $2.5 . \%$, opiates $0.0 \%$, levothyroxine $7.5 \%$.

Following medications (SOC) for mitigating COVID-19 symptoms, that were prescribed by head physicians to the patients, were reported in group B: Salbutamol 27.5\%, ASA 35.0\%, NSAIDs 12.5\%, Azithromycin 37.5\%, Nebulizers 5.0\%, Ivermectin 10.0\%, Enoxaparin 0.0\%, Heparin 0.0\%, Hydroxychloroquine 0.0\%, Corticosteroids $10.0 \%$, Oxygen therapy $2.5 \%$, Antihistamines $0.0 \%$, Anti-influenza drugs $2.5 \%$, Antipyretics $62.5 \%$, Antibiotics $7.5 \%$. 
Likewise, the discomforts that occurred after the use of CA in the research subjects were evaluated, finding the following effects for nasal spray administration: Nasal itching $91.4 \%$, oropharyngeal discomfort $85.7 \%$, dizziness $28.6 \%$, nausea $37,1 \%$, headache $65.71 \%$, slight increase in heart rate $8.6 \%$, hypotension $5.7 \%$, rhinorrhea $34.3 \%$, lacrimation $71.4 \%$, general malaise $40 \%$.

No discomforts were observed among any patient in the oral drops intake. In the more intrusive but more therapeutical designed route of administration trough nasal spray application the duration of discomforts remained only for a few days (see table 1). Discomforts only remained for a few minutes after each application (7.21 minutes as average for all discomforts with SD of 4,22556) -as expected-and each of them was taken into account as the difference between the moment when it was presented and the moment when it was resolved.

\section{Table1. CA's DISCOMFORT IN NASAL SPRAY ADMINISTRATION (days)}

\begin{tabular}{|c|c|c|c|c|c|}
\hline & $\mathbf{N}$ & Minimum duration in days & Maximum duration in days & Median duration in days & SD \\
\hline Nasal itching & 32 & 0 & 14 & 8.51 & 4.20343 \\
\hline Oropharyngeal discomfort & 30 & 0 & 14 & 6.29 & 4.30848 \\
\hline Dizziness & 10 & 0 & 5 & 0.80 & 1.38903 \\
\hline Nausea & 13 & 0 & 8 & 1.34 & 2.14123 \\
\hline Headache & 23 & 0 & 9 & 3.06 & 2.90984 \\
\hline $\begin{array}{l}\text { Slight increase in heart } \\
\text { rate }\end{array}$ & 3 & 0 & 5 & 0.40 & 1.33284 \\
\hline Hypotension & 2 & 0 & 5 & 0.20 & 0.90097 \\
\hline Rhinorrhea & 4 & 0 & 11 & 1.37 & 2,45051 \\
\hline Lacrimation & 13 & 0 & 14 & 7.03 & 5,39327 \\
\hline General malaise & 6 & 0 & 11 & 2.77 & 3,71076 \\
\hline
\end{tabular}

An analysis was carried out through the calculation of the OR and the corresponding expected impact for each variable that were evaluated in the study, the OR values with their $95 \%$ confidence intervals, presented in table 2 .

Table 2. Evaluation between intervention group and control group 


\begin{tabular}{|l|l|l|l|}
\hline Variable & OR & IC & P value \\
\hline Fever & 0,897 & $0,36-2,23$ & 0,816 \\
\hline Cough & 0,571 & $0,17-0,93$ & $0,017^{*}$ \\
\hline Dyspnea & 0,460 & $0,12-1,15$ & 0,799 \\
\hline Muscle fatigue & 0,250 & $0,05-1,28$ & 0,077 \\
\hline Cephalea & 0,570 & $0,16-1,92$ & 0,363 \\
\hline Ageusia & 0,150 & $0,06-0,92$ & $0,037^{*}$ \\
\hline Anosmia & 0,650 & $0,56-0,85$ & $0,049 *$ \\
\hline Chest tightness & 1,350 & $0,56-3,25$ & 0,502 \\
\hline General malaise & 0,316 & $0,03-3,18$ & 0,305 \\
\hline Nasal Congestion & 0,890 & $0,35-2,30$ & 0,809 \\
\hline
\end{tabular}

\section{* $\mathrm{P}$ value $<0,05$ statistical significance}

In relation to the $O R$ values, the variables fever $(O R=0.897)$ Figure 1 , Cough, $(O R=0.571)$ Figure 2 , Dyspnea $(O R=0.460)$ Figure 3, Muscle fatigue $(O R=0.250)$ Figure 4 , Cephalea $(O R=0,570)$ Figure 5 , Ageusia $(O R=0.150)$ Figure 6 , Anosmia $(O R=0.650)$ Figure 7 , General malaise $(O R=0.316)$ Figure 9 , Nasal congestion $(\mathrm{OR}=0.890)$ figure 10 , are less than 1 , making the use of $\mathrm{CA}$ a protective factor, thus showing improvement in these symptoms after its use compared to the control group. Chest tightness $(O R=1,350)$ Figure 8 , although it presents an $O R$ value greater than 1 , it also present confidence intervals that cross 1 , this being inconclusive that they do not favor the reduction of said symptoms.

The expected impact is the difference in the distance of change or difference that occurs at the time of measuring the event in days, that is, it defines whether there is a change in the experimental group vs. the control group in the reduction of each of the events (symptoms). P value confirms that there is a statistically significant difference between the intervention group and the control group.

\subsection{Figures}

Figure1. Graphic compares CA vs control in terms of expected impact on fever duration in days. OR: 0.897.

Figure 2. Graphic compares CA vs control in terms of expected impact on cough duration in days. OR: 0.571 . 
Figure 3. Graphic compares CA vs control in terms of expected impact on dyspnea duration in days. OR: 0.460 .

Figure 4. Graphic compares CA vs control in terms of expected impact on Muscle fatigue duration in days. OR: 0.250 .

Figure 5. Graphic compares CA vs control in terms of expected impact on Cephalea duration in days. OR: 0.570 .

Figure 6. Graphic compares CA vs control in terms of expected impact of Ageusia duration in days. OR: 0.150 .

Figure 7. Graphic compares CA vs control in terms of expected impact on Anosmia duration in days. OR: 0.650

Figure 8. Graphic compares CA vs control in terms of expected impact on Chest tightness duration in days. OR: 1.350 .

Figure 9. Graphic compares CA vs control in terms of expected impact on General Malaise. OR: 0.316.

Figure 10. Graphic compares CA vs control in terms of expected impact on Nasal Congestion. OR: 0.890. 


\section{DISCUSSION}

\subsection{Observations around the results}

CA drug showed to be a protective factor for fever, cough, dyspnea (probably the worst indicator for COVID-19), muscle fatigue, cephalea, ageusia, anosmia, general malaise, and nasal congestion with an OR are less than 1, without ruling out the possibility that the drug may be also effective in larger-sample studies chest tightness.

\subsection{The need of a specific drug against COVID-19 with a potential for covering new strains and other} existing or to appear beta-coronaviruses

In the absence of effective drugs to fight COVID-19 the validation of the nicotinic hypothesis in humans is of critical relevance, since the CA drug is of rapid development, low cost and exhibits tolerance and safety in agreement with other drugs of the same category.

New strains of SARS-CoV-2 with several mutations or variations of concern (VOCs) $(76,77)$ in the spike protein have been discovered since November 2020 in various countries and are spreading very fast. There are serious concerns of increased mortality risk for current existing VOCs (78). This could potentially compromise current COVID-19 vaccines (79) trough immune escape as is already the case with many other viruses. CA has a particular mechanism of action, that evades the mutagenesis problem of SARSCOV-2, being thus of potential application in all current existing VOCs and in other future strains of SARSCoV-2 covering most likely future appearances of new coronaviruses, as well as existing coronaviruses, such as those of the common cold. This should be studied further.

Accordingly to Lagoumintzis et al. (80) a "toxin-like" epitope on the Spike Glycoprotein has been reported having interestingly protein complexes that involve a vast part of the "toxin-like" sequences of SARS-CoV-1 and SARS-CoV-2 Spike glycoproteins and toxin binding site of human $\alpha 7 n A C h R$. Probably, too much attention has been driven to the RBD of ACE2-S Glycoprotein, ignoring that one thing is the binding and infectivity capacity of the virus through the RBD of ACE2 and another thing is the interactions with epitopes that do not interfere with ACE2 but can be determinants in the lethality and severe progression of the disease. A different approach going beyond the binding interactions of betacoronaviruses with ACE2 by focusing more on the disruptive interactions of this family of viruses with other epitopes is essential. It could be the key to reducing the lethality and severe forms of disease by betacoronaviruses such as the common cold, SARS-CoV-1 and SARS-CoV-2. This way, the efforts should not only be directed to a design for only avoiding binding with the RBD of ACE2 but towards the development of new drugs capable of antagonizing alternative disruptions in epitopes such as those related to nAChR. In view of the appearance of currently and future VOCs or even new betacoronaviruses, a convenient strategy would be, therefore, to tackle the complications derived from the disruption of the cholinergic and immune system by modulating hyperinflammation and immune deregulation processes, which would fight lethality and complications due to viremia through an alternative mechanism, in an independent way, making less relevant the capacity of infectivity and mutagenesis of such viruses. 


\subsection{The long Covid: a coming public health's issue challenge}

It is also important to point out the therapeutic potential to be explored of CA in the cases of "Long Covid". In the absence of more conclusive studies, preliminary data from studies published to date (81-85) indicate that between $10 \%$ to $53 \%$ of those infected with SARS-CoV-2, including especially also healthy youth and adults with no history of comorbidities and mostly not hospitalized, who passed the COVID-19 in a mild manner reaching a prevalence of $80 \%$ in the sequelae at 3 months in this subgroup according to a study by Göertz et al. (86), suffer preliminary neurological sequelae such as mental fog, fatigue, headache, shortness of breath, muscle pain and moderate damage to heart, lung, kidney, liver and pancreas. According to a CDC Morbidity and Mortality Weekly Report (87), 35\% of patients had not returned to their usual state of health when interviewed $2 / 3$ weeks after the test. Although it is still early to have clear scientific evidence on the impact of long-Covid, it is very likely that persistent symptoms exist for weeks, months or even years in a significant number of patients. This phenomenon was described by the WHO and by two studies $(88,89)$ showing persistent symptoms as impaired exercise capacity and health for 24 months in the case of survivors of SARS-CoV-1 in 2003. About $40 \%$ of people recovering from SARS-CoV-1 had to deal with symptoms of chronic fatigue even 3.5 years after they had overcome the illness. Although it has yet to be determined, the ravages of Long-Covid should not be underestimated and are a source of logical concern. A reason for Long-Covid could be the endocytosis that SARS-CoV-2 performs on ACE2. ACE2 mid or long-term downregulation could turn into a more or less chronic or prolonged RAAS axis imbalance in Long-covid patients. Thus, RAAS' ability to return to homeostasis of the lung, kidney, heart, or other organs would be impaired. Another reason could be the involvement in the CNS by the neurotropism of SARS-CoV-2 being at the base of the symptoms of Long-Covid. Also, an alteration, short-circuiting or disruption of the immune system through the SN and Immune System interface with macrophage interactions or an alteration of the cholinergic anti-inflammatory system could explain the persisting symptoms of Long-Covid. Therefore, it is necessary and urgent to address a therapeutic approach for this Long-Covid or Post-Covid Syndrome that will most likely affect millions of people. In this context, cholinergic agonists should be further studied and, if their therapeutic action during infection is further confirmed and validated, the same therapeutic action could also be valid to address the therapeutic management of Long-Covid symptoms since the same mechanism of action that offers therapeutic advantages during infection could offer a promise of accelerated recovery in Long-Covid symptoms. This should be further examined.

\section{CONCLUSION}

Despite the limitation of study in the sample of patients, the positive results obtained on the symptoms caused by COVID-19 using cholinergic agonists molecules in humans infected by SARS-CoV-2 versus the control group, opens the door to a promising therapeutic approach in fighting COVID-19. Larger multicentrical double blind randomized trials in humans are encouraged in the light of the previous existent evidence. The preliminary evidence of nicotine's therapeutic potential and other cholinergic molecules trough medicinal administration in several other diseases and the safety and well-known 
tolerance of NRT's products approved by regulatory agencies as over-the-counter products -even for pregnant women- are also valuable for partially endorsing a safe and therapeutic approach on COVID-19. Tolerance to the drug was good, mild side effects lasted only a few minutes as expected in liquid nasal application of cholinergic agonists that enhance the vagal reflex, and it correlates with the tolerance and safety observed in other drugs such as NRTs.

This is study in humans shows preliminary evidence on the therapeutic effect against COVID-19 of cholinergic agonist molecules trough a specific pharmacological design and with combined oral and nasal administration routes, and could preliminarily strength the clinical observations of the low prevalence of smokers observed among COVID-19 infected patients, explaining the paradox about smoking being itself a dangerous and not recommended tool to combat COVID-19 but that nicotine and/or other cholinergic agonists molecules could offer a promising therapeutic tool when administered in a medicinal way and imitating most common viral entry route through the olfactory mucosa. The study shows preliminary effectiveness of use of cholinergic agonist agents having the capacity to antagonize with SARS-CoV-2 probably either at the RBD of the ACE2, or at the "Toxin-like-site" in disruptive interaction with the nAChRs. The cholinergic mechanism of action of nicotinic agonists could explain the regulation of hyperinflammatory processes linked to malfunctioning of the RAAS by viremia, the regulation the cholinergic anti-inflammatory system or of immune dysfunctions linked to failures in the interface of the ADAM17/TNF-a modulation. However, larger multicenter studies should be conducted to gather more clinical and scientific evidence.

\section{LIMITATIONS OF THE STUDY}

Sample size: The study results are limited to the number of patients included in it, 80 (40 for intervention group and 40 for control group). This has been a randomized open-label trial pilot study. It is suggested that the same study be conducted with larger multicentrically studies that include higher number of patients in both groups with double blind randomized trials with placebo group.

\section{AUTHOR'S STATEMENTS}

The authors hereby declare:

- The authors of this study do not promote the use of the smoked cigarette on the contrary, they advise against it under any circumstances, and they are not promoting or encouraging the use of alternative products such as electronic cigarettes for harm-reduction or smoking cessation products as NRT's for fighting COVID-19. This is another discussion.

- It is of interest to the authors to point out that although the smoked cigarette and its added components and smoked route of administration are clearly harmful, the tobacco plant and cholinergic agonist molecules are of therapeutic interest in the COVID-19 disease if they are treated and explored in a scientific and medicinal way, leaving aside controversies and stigmatizations that may well apply to the industry and the consumption of cigarettes, but should not be mixed with the therapeutic potential of medicinal drugs based on such molecules with a scientific pharmacological design and from a pure medical perspective for the benefit of human health. 


\section{FUNDING STAMEMENT}

This study did not receive any specific grant from funding agencies in the public, commercial, or not-forprofit sectors. The authors have not obtained any funding from the tobacco industry, nor from the vaping industry nor NRT-related products companies.

\section{CREDIT AUTHORSHIP CONTRIBUTION STATEMENT}

León Higuera J.G.: Methodology, Investigation, Conceptualization, Supervision; Restrepo Guerrero F.H: Software, statistical analysis; León García M.: review \& supervision; Politi M.: review, supervision; Mendive F.: project advisor, review \& editing; Angulo OJ.: Conceptualization, Supervision, Writing original draft, Writing-, review \& editing.

\section{DECLARATION OF COMPETING INTEREST}

The authors report no declarations of interest.

\section{ACKNOWLEDGEMENTS}

Not applicable

\section{COPYRIGHT}

All images and graphics in this article are of own development and property of the authors. No external images have been used involving third party copyrights.

\section{REFERENCES}

1. Repurposed Antiviral Drugs for Covid-19 - Interim WHO Solidarity Trial Results. N Engl J Med [Internet]. 2020 Dec 2;NEJMoa2023184. Available from: http://www.nejm.org/doi/10.1056/NEJMoa2023184 2. Changeux J-P, Amoura Z, Rey FA, Miyara M. A nicotinic hypothesis for Covid-19 with preventive and therapeutic implications. Comptes Rendus Biol [Internet]. 2020 Jun 5;343(1):33-9. Available from: https://comptes-rendus.academie-sciences.fr/biologies/item/CRBIOL_2020_343_1_33_0

3. Farsalinos K, Niaura R, Le Houezec J, Barbouni A, Tsatsakis A, Kouretas D, et al. Editorial: Nicotine and SARS-CoV-2: COVID-19 may be a disease of the nicotinic cholinergic system. Toxicol Reports [Internet]. 2020;7:658-63. Available from: https://linkinghub.elsevier.com/retrieve/pii/S2214750020302924 4. Mo P, Xing Y, Xiao Y, Deng L, Zhao Q, Wang H, et al. Clinical characteristics of refractory COVID-19 pneumonia in Wuhan, China. Clin Infect Dis [Internet]. 2020 Mar 16; Available from: https://academic.oup.com/cid/advance-article/doi/10.1093/cid/ciaa270/5805508 5. Chow N, Fleming-Dutra K, Gierke R, Hall A, Hughes M, Pilishvili T, et al. Preliminary Estimates of the Prevalence of Selected Underlying Health Conditions Among Patients with Coronavirus Disease 2019 United States, February 12-March 28, 2020. MMWR Morb Mortal Wkly Rep [Internet]. 2020 Apr 3;69(13):382-6. Available from: http://www.cdc.gov/mmwr/volumes/69/wr/mm6913e2.htm? s_cid $=$ mm6913e2_w

6. Fu L, Wang B, Yuan T, Chen X, Ao Y, Fitzpatrick T, et al. Clinical characteristics of coronavirus disease 2019 (COVID-19) in China: A systematic review and meta-analysis. J Infect [Internet]. 2020 Jun;80(6):65665. Available from: https://linkinghub.elsevier.com/retrieve/pii/S0163445320301705 
7. Petrilli CM, Jones SA, Yang J, Rajagopalan H, O'Donnell L, Chernyak Y, et al. Factors associated with hospital admission and critical illness among 5279 people with coronavirus disease 2019 in New York City: prospective cohort study. BM] [Internet]. 2020 May 22;m1966. Available from:

https://www.bmj.com/lookup/doi/10.1136/bmj.m1966

8. Farsalinos K, Barbouni A, Niaura R. Systematic review of the prevalence of current smoking among hospitalized COVID-19 patients in China: could nicotine be a therapeutic option? Intern Emerg Med [Internet]. 2020 Aug 9;15(5):845-52. Available from: http://link.springer.com/10.1007/s11739-020-02355-7 9. González-Rubio J, Navarro-López C, López-Nájera E, López-Nájera A, Jiménez-Díaz L, Navarro-López JD, et al. A Systematic Review and Meta-Analysis of Hospitalised Current Smokers and COVID-19. Int J Environ Res Public Health [Internet]. 2020 Oct 11;17(20):7394. Available from: https://www.mdpi.com/1660-4601/17/20/7394

10. Farsalinos K, Barbouni A, Poulas K, Polosa R, Caponnetto P, Niaura R. Current smoking, former smoking, and adverse outcome among hospitalized COVID-19 patients: a systematic review and metaanalysis. Ther Adv Chronic Dis [Internet]. 2020 Jan 25;11:204062232093576. Available from: http://journals.sagepub.com/doi/10.1177/2040622320935765

11. Gonzalez-Rubio J, Navarro-Lopez C, Lopez-Najera E, Lopez-Najera A, Jimenez-Diaz L, Navarro-Lopez JD, et al. Cytokine Release Syndrome (CRS) and Nicotine in COVID-19 Patients: Trying to Calm the Storm. Front Immunol [Internet]. 2020 Jun 11;11. Available from:

https://www.frontiersin.org/article/10.3389/fimmu.2020.01359/full

12. Nicovid Prev APHP [Internet]. Available from: https://www.aphp.fr/contenu/lassistance-publiquehopitaux-de-paris-lance-une-etude-nationale-pour-evaluer-lefficacite--0

13. Greenland S, Satterfield MH, Lanes SF. A Meta-Analysis to Assess the Incidence of Adverse Effects Associated with the Transdermal Nicotine Patch. Drug Saf [Internet]. 1998;18(4):297-308. Available from: http://link.springer.com/10.2165/00002018-199818040-00005

14. Kem WR, Mahnir VM, Papke RL, Lingle CJ. Anabaseine is a potent agonist on muscle and neuronal alpha- bungarotoxin-sensitive nicotinic receptors. J Pharmacol Exp Ther. 1997;283(3):979-92.

15. Villafane G, Thiriez C, Audureau E, Straczek C, Kerschen P, Cormier-Dequaire F, et al. High-dose transdermal nicotine in Parkinson's disease patients: a randomized, open-label, blinded-endpoint evaluation phase 2 study. Eur J Neurol [Internet]. 2018 Jan;25(1):120-7. Available from: http://doi.wiley.com/10.1111/ene.13474

16. Newhouse P, Kellar K, Aisen P, White H, Wesnes K, Coderre E, et al. Nicotine treatment of mild cognitive impairment: A 6-month double-blind pilot clinical trial. Neurology [Internet]. 2012 Jan 10;78(2):91-101. Available from: http://www.neurology.org/cgi/doi/10.1212/WNL.0b013e31823efcbb 17. Schnoll RA, Goelz PM, Veluz-Wilkins A, Blazekovic S, Powers L, Leone FT, et al. Long-term Nicotine Replacement Therapy. JAMA Intern Med [Internet]. 2015 Apr 1;175(4):504. Available from: http://archinte.jamanetwork.com/article.aspx?doi=10.1001/jamainternmed.2014.8313 18. Villafane G, Cesaro P, Rialland A, Baloul S, Azimi S, Bourdet C, et al. Chronic high dose transdermal 
nicotine in Parkinson's disease: An open trial. Eur J Neurol. 2007;14(12):1313-6.

19. Benowitz NL, Hansson A, Jacob P. Cardiovascular Effects of Nasal and Transdermal Nicotine and Cigarette Smoking. Hypertension [Internet]. 2002 Jun;39(6):1107-12. Available from: https://www.ahajournals.org/doi/10.1161/01.HYP.0000018825.76673.EA

20. Kimmel SE, Berlin JA, Miles C, Jaskowiak J, Carson JL, Strom BL. Risk of acute first myocardial infarction and use of nicotine patches in a general population. J Am Coll Cardiol [Internet]. 2001 Apr;37(5):1297-302. Available from: https://linkinghub.elsevier.com/retrieve/pii/S073510970101124X 21. Joseph AM, Norman SM, Ferry LH, Prochazka A V., Westman EC, Steele BG, et al. The Safety of Transdermal Nicotine as an Aid to Smoking Cessation in Patients with Cardiac Disease. N Engl J Med [Internet]. 1996 Dec 12;335(24):1792-8. Available from: http://www.nejm.org/doi/abs/10.1056/NEJM199612123352402

22. Ware JH, Vetrovec GW, Miller AB, Van Tosh A, Gaffney M, Yunis C, et al. Cardiovascular Safety of Varenicline. Am J Ther [Internet]. 2013 Apr;1. Available from: http://journals.Iww.com/00045391$900000000-99413$

23. Woolf KJ, Zabad MN, Post JM, McNitt S, Williams GC, Bisognano JD. Effect of nicotine replacement therapy on cardiovascular outcomes after acute coronary syndromes. Am J Cardiol. 2012;110(7):968-70. 24. Benowitz NL, Gourlay SG. Cardiovascular Toxicity of Nicotine: Implications for Nicotine Replacement Therapy 11All editorial decisions for this article, including selection of referees, were made by a Guest Editor. This policy applies to all articles with authors from the Universi. J Am Coll Cardiol [Internet]. 1997 Jun;29(7):1422-31. Available from: https://linkinghub.elsevier.com/retrieve/pii/S073510979700079X 25. Zevin S, Jacob P, Benowitz NL. Dose-related cardiovascular and endocrine effects of transdermal nicotine*. Clin Pharmacol Ther [Internet]. 1998 Jul;64(1):87-95. Available from: http://doi.wiley.com/10.1016/S0009-9236(98)90026-1

26. Apelberg BJ, Onicescu G, Avila-Tang E, Samet JM. Estimating the Risks and Benefits of Nicotine Replacement Therapy for Smoking Cessation in the United States. Am J Public Health [Internet]. 2010 Feb;100(2):341-8. Available from: http://ajph.aphapublications.org/doi/10.2105/AJPH.2008.147223 27. Hecht SS. Tobacco carcinogens, their biomarkers and tobacco-induced cancer. Nat Rev Cancer [Internet]. 2003 Dec;3(10):733-44. Available from: http://www.nature.com/articles/nrc1190

28. Fishbein L, O'Brien P, Hutson A, Theriaque D, Stacpoole PW, Flotte T. Pharmacokinetics and pharmacodynamic effects of nicotine nasal spray devices on cardiovascular and pulmonary function. J Investig Med. 2000;48(6):435-40.

29. C. SK, Kumar SA, Wei H. Comparative docking studies to understand the binding affinity of nicotine with soluble ACE2 (SACE2)-SARS-CoV-2 complex over SACE2. Toxicol Reports [Internet]. 2020;7:1366-72. Available from: https://linkinghub.elsevier.com/retrieve/pii/S2214750020304108

30. Mohammadi S, Heidarizadeh M, Entesari M, Esmailpour A, Esmailpour M, Moradi R, et al. In silico Investigation on the Inhibiting Role of Nicotine/Caffeine by Blocking the S Protein of SARS-CoV-2 Versus ACE2 Receptor. Microorganisms [Internet]. 2020 Oct 17;8(10):1600. Available from: 
https://www.mdpi.com/2076-2607/8/10/1600

31. Farsalinos K, Eliopoulos E, Leonidas DD, Papadopoulos GE, Tzartos S, Poulas K. Molecular modelling and docking experiments examining the interaction between SARS-CoV-2 spike glycoprotein and neuronal nicotinic acetylcholine receptors. Prepr 2020, [Internet]. 2020;(May):1-29. Available from: www.preprints.org

32. Steardo L, Steardo L, Zorec R, Verkhratsky A. Neuroinfection may contribute to pathophysiology and clinical manifestations of COVID-19. Acta Physiol [Internet]. 2020;229(3). Available from: https://onlinelibrary.wiley.com/doi/abs/10.1111/apha.13473

33. Qiao J, Li W, Bao J, Peng Q, Wen D, Wang J, et al. The expression of SARS-CoV-2 receptor ACE2 and CD147, and protease TMPRSS2 in human and mouse brain cells and mouse brain tissues. Biochem Biophys Res Commun [Internet]. 2020 Dec;533(4):867-71. Available from: https://linkinghub.elsevier.com/retrieve/pii/S0006291X20317836

34. Farsalinos K, Angelopoulou A, Alexandris N, Poulas K. COVID-19 and the nicotinic cholinergic system. Eur Respir J [Internet]. 2020 Jul;56(1):2001589. Available from:

http://erj.ersjournals.com/lookup/doi/10.1183/13993003.01589-2020

35. Clerkin KJ, Fried JA, Raikhelkar J, Sayer G, Griffin JM, Masoumi A, et al. COVID-19 and Cardiovascular Disease. Circulation [Internet]. 2020 May 19;141(20):1648-55. Available from: https://www.ahajournals.org/doi/10.1161/CIRCULATIONAHA.120.046941

36. Saraiya T, Farsalinos K, Poulas K, Labrou D. Implications of the SARS-CoV-2 spike protein interaction with type-1 macrophages via $\alpha$ 7-nAChR. Qeios [Internet]. 2021 Mar 16; Available from: https://www.qeios.com/read/26GTOD

37. DeDiego ML, Nieto-Torres JL, Regla-Nava JA, Jimenez-Guardeno JM, Fernandez-Delgado R, Fett C, et al. Inhibition of NF- B-Mediated Inflammation in Severe Acute Respiratory Syndrome Coronavirus-Infected Mice Increases Survival. J Virol [Internet]. 2014 Jan 15;88(2):913-24. Available from: https://jvi.asm.org/content/88/2/913

38. Echeverri R. NP, Mockus S. I. Nuclear factor KB (NF-kB): Signalosoma and its importance in cancer and inflammatories diseases. Rev Fac Med. 2008;56(2):133-46.

39. Sugano N, Shimada K, Ito K, Murai S. Nicotine inhibits the production of inflammatory mediators in U937 cells through modulation of Nuclear Factor-kB activation. Biochem Biophys Res Commun. $1998 ; 252(1): 25-8$.

40. Jiao ZY, Wu J, Liu C, Wen B, Zhao WZ, Du XL. Nicotinic $\alpha 7$ receptor inhibits the acylation stimulating protein-induced production of monocyte chemoattractant protein-1 and keratinocyte-derived chemokine in adipocytes by modulating the p38 kinase and nuclear factor-kB signaling pathways. Mol Med Rep. 2016;14(4):2959-66.

41. Mahmud-Al-Rafat A, Muzammal Haque Asim M, Taylor-Robinson AW, Majumder A, Muktadir A, Muktadir $\mathrm{H}$, et al. A combinational approach to restore cytokine balance and to inhibit virus growth may promote patient recovery in severe COVID-19 cases. Cytokine [Internet]. 2020 Dec;136:155228. Available 
from: https://linkinghub.elsevier.com/retrieve/pii/S1043466620302441

42. Heurich A, Hofmann-Winkler H, Gierer S, Liepold T, Jahn O, Pohlmann S. TMPRSS2 and ADAM17 Cleave ACE2 Differentially and Only Proteolysis by TMPRSS2 Augments Entry Driven by the Severe Acute Respiratory Syndrome Coronavirus Spike Protein. J Virol. 2014;88(2):1293-307.

43. Ingraham NE, Barakat AG, Reilkoff R, Bezdicek T, Schacker T, Chipman JG, et al. Understanding the renin-angiotensin-aldosterone-SARS-CoV axis: a comprehensive review. Eur Respir J [Internet]. 2020 Jul;56(1):2000912. Available from: http://erj.ersjournals.com/lookup/doi/10.1183/13993003.00912-2020 44. Song P, Li W, Xie J, Hou Y, You C. Cytokine storm induced by SARS-CoV-2. Clin Chim Acta [Internet]. 2020 Oct;509:280-7. Available from: https://linkinghub.elsevier.com/retrieve/pii/S0009898120302813 45. Djaldetti, M BH. Nicotine Modifies Cytokine Production by Human Mononuclears Stimulated by Colon Cancer Cells. Color Cancer Open Access. 2017;03(02).

46. Sethi G, Sung B, Aggarwal BB. TNF: A master switch for inflammation to cancer. Front Biosci. 2008;13(13):5094-107.

47. Zhou F, Yu T, Du R, Fan G, Liu Y, Liu Z, et al. Clinical course and risk factors for mortality of adult inpatients with COVID-19 in Wuhan, China: a retrospective cohort study. Lancet. 2020;395(10229):105462.

48. Huang C, Wang Y, Li X, Ren L, Zhao J, Hu Y, et al. Clinical features of patients infected with 2019 novel coronavirus in Wuhan, China. Lancet [Internet]. 2020 Feb;395(10223):497-506. Available from: https://linkinghub.elsevier.com/retrieve/pii/S0140673620301835

49. Tegally H, Wilkinson E, Lessells RJ, Giandhari J, Pillay S, Msomi N, et al. Sixteen novel lineages of SARS-CoV-2 in South Africa. Nat Med [Internet]. 2021 Mar 2;27(3):440-6. Available from:

http://www.nature.com/articles/s41591-021-01255-3

50. Kuba K, Imai Y, Rao S, Gao H, Guo F, Guan B, et al. A crucial role of angiotensin converting enzyme 2 (ACE2) in SARS coronavirus-induced lung injury. Nat Med [Internet]. 2005 Aug 10;11(8):875-9. Available from: http://www.nature.com/articles/nm1267

51. Mendoza A, Lazartigues E. The compensatory renin-angiotensin system in the central regulation of arterial pressure: new avenues and new challenges. Ther Adv Cardiovasc Dis [Internet]. 2015 Aug 23;9(4):201-8. Available from: http://journals.sagepub.com/doi/10.1177/1753944715578056

52. Ulloa L. The vagus nerve and the nicotinic anti-inflammatory pathway. Nat Rev Drug Discov [Internet]. 2005 Aug;4(8):673-84. Available from: http://www.nature.com/articles/nrd1797 53. Fudim M, Qadri YJ, Ghadimi K, MacLeod DB, Molinger J, Piccini JP, et al. Implications for Neuromodulation Therapy to Control Inflammation and Related Organ Dysfunction in COVID-19. J Cardiovasc Transl Res [Internet]. 2020 Dec 26;13(6):894-9. Available from: http://link.springer.com/10.1007/s12265-020-10031-6

54. Tracey KJ. The inflammatory reflex. Nature [Internet]. 2002 Dec;420(6917):853-9. Available from: http://www.nature.com/articles/nature01321

55. Parrish WR, Rosas-Ballina M, Gallowitsch-Puerta M, Ochani M, Ochani K, Yang L-H, et al. Modulation 
of TNF Release by Choline Requires $\alpha 7$ Subunit Nicotinic Acetylcholine Receptor-Mediated Signaling. Mol Med [Internet]. 2008 Sep 20;14(9-10):567-74. Available from:

https://molmed.biomedcentral.com/articles/10.2119/2008-00079.Parrish

56. Yu M, Ochani M, Amella CA, Tanovic M, Susarla S, Li JH, et al. Nicotinic acetylcholine receptor alpha7 subunit is an essential regulator of inflammation. Nature [Internet]. 2003;421(6921):384-8. Available from: https://pubmed.ncbi.nIm.nih.gov/12508119/\%0Ahttp://www.ncbi.nlm.nih.gov/pubmed/12508119\%0Apapers3 ://publication/uuid/1F1A5EDA-A6EF-4583-9859-72306FE8AB4C

57. Farsalinos K, Eliopoulos E, Leonidas DD, Papadopoulos GE, Tzartos S, Poulas K. Nicotinic Cholinergic System and COVID-19: In Silico Identification of an Interaction between SARS-CoV-2 and Nicotinic Receptors with Potential Therapeutic Targeting Implications. Int J Mol Sci [Internet]. 2020 Aug 13;21(16):5807. Available from: https://www.mdpi.com/1422-0067/21/16/5807

58. Lakhan SE, Kirchgessner A. Anti-inflammatory effects of nicotine in obesity and ulcerative colitis. J Transl Med [Internet]. 2011 Dec 2;9(1):129. Available from: https://translationalmedicine.biomedcentral.com/articles/10.1186/1479-5876-9-129

59. Sandborn WJ. Transdermal Nicotine for Mildly to Moderately Active Ulcerative Colitis. Ann Intern Med [Internet]. 1997 Mar 1;126(5):364. Available from: http://annals.org/article.aspx?doi=10.7326/0003-4819126-5-199703010-00004

60. Benowitz NL, Hukkanen J, Jacob P. Nicotine Chemistry, Metabolism, Kinetics and Biomarkers. In 2009. p. 29-60. Available from: http://link.springer.com/10.1007/978-3-540-69248-5_2

61. Fant R V., Henningfield JE, Shiffman S, Strahs KR, Reitberg DP. A pharmacokinetic crossover study to compare the absorption characteristics of three transdermal nicotine patches. Pharmacol Biochem Behav. 2000;67(3):479-82.

62. McGehee DS, Heath MJS, Gelber S, Devay P, Role LW. Nicotine enhancement of fast excitatory synaptic transmission in CNS by presynaptic receptors. Science (80- ). 1995;269(5231):1692-6.

63. Mehta P, McAuley DF, Brown M, Sanchez E, Tattersall RS, Manson JJ. COVID-19: consider cytokine storm syndromes and immunosuppression. Lancet [Internet]. 2020 Mar;395(10229):1033-4. Available from: https://linkinghub.elsevier.com/retrieve/pii/S0140673620306280

64. Borovikova L V., Ivanova S, Zhang M, Yang H, Botchkina GI, Watkins LR, et al. Vagus nerve stimulation attenuates the systemic inflammatory response to endotoxin. Nature. 2000;405(6785):458-62. 65. Pavlov VA, Tracey KJ. The vagus nerve and the inflammatory reflex-linking immunity and metabolism. Nat Rev Endocrinol [Internet]. 2012 Dec 21;8(12):743-54. Available from: http://www.nature.com/articles/nrendo.2012.189

66. Qi Y, Si D, Zhu L, Qi Y, Wu Z, Chen D, et al. High-fat diet-induced obesity affects alpha 7 nicotine acetylcholine receptor expressions in mouse lung myeloid cells. Sci Rep [Internet]. 2020 Dec 27;10(1):18368. Available from: http://www.nature.com/articles/s41598-020-75414-w

67. Noviello CM, Gharpure A, Mukhtasimova N, Cabuco R, Baxter L, Borek D, et al. Structure and gating mechanism of the $\alpha 7$ nicotinic acetylcholine receptor. Cell [Internet]. 2021 Mar; Available from: 
https://linkinghub.elsevier.com/retrieve/pii/S0092867421002385

68. Mikulski Z, Hartmann P, Jositsch G, Zasłona Z, Lips KS, Pfeil U, et al. Nicotinic receptors on rat alveolar macrophages dampen ATP-induced increase in cytosolic calcium concentration. Respir Res [Internet]. 2010 Dec 29;11(1):133. Available from: http://respiratoryresearch.biomedcentral.com/articles/10.1186/1465-9921-11-133

69. Bell JH, Herrera AH, Li Y, Walcheck B. Role of ADAM17 in the ectodomain shedding of TNF- and its receptors by neutrophils and macrophages. J Leukoc Biol [Internet]. 2007 Apr 23;82(1):173-6. Available from: http://doi.wiley.com/10.1189/jlb.0307193

70. Palau V, Riera M, Soler MJ. ADAM17 inhibition may exert a protective effect on COVID-19. Nephrol Dial Transplant [Internet]. 2020 Jun 1;35(6):1071-2. Available from:

https://academic.oup.com/ndt/article/35/6/1071/5820263

71. Oakes JM, Fuchs RM, Gardner JD, Lazartigues E, Yue X. Nicotine and the renin-angiotensin system. Am J Physiol Integr Comp Physiol [Internet]. 2018 Nov 1;315(5):R895-906. Available from:

https://www.physiology.org/doi/10.1152/ajpregu.00099.2018

72. Alexandris N, Lagoumintzis G, Chasapis CT, Leonidas DD, Papadopoulos GE, Tzartos SJ, et al. Nicotinic cholinergic system and COVID-19: In silico evaluation of nicotinic acetylcholine receptor agonists as potential therapeutic interventions. Toxicol Reports [Internet]. 2021;8:73-83. Available from: https://linkinghub.elsevier.com/retrieve/pii/S2214750020304583

73. Caronna E, Ballvé A, Llauradó A, Gallardo VJ, Ariton DM, Lallana S, et al. Headache: A striking prodromal and persistent symptom, predictive of COVID-19 clinical evolution. Cephalalgia [Internet]. 2020 Nov 4;40(13):1410-21. Available from: http://journals.sagepub.com/doi/10.1177/0333102420965157 74. Peng K-P. Association between COVID-19 and headache: What evidence and history tell us. Cephalalgia [Internet]. 2020 Nov 4;40(13):1403-5. Available from:

http://journals.sagepub.com/doi/10.1177/0333102420965969

75. Wedderburn L, Peckham H, De Gruijter N, Raine C, Radziszewska A, Ciurtin C, et al. Male sex identified by global COVID-19 meta-analysis as a risk factor for death and ITU admission. Nat Commun [Internet]. 2020; Available from: http://library1.nida.ac.th/termpaper6/sd/2554/19755.pdf

76. da Silva Filipe A, Shepherd JG, Williams T, Hughes J, Aranday-Cortes E, Asamaphan P, et al. Genomic epidemiology reveals multiple introductions of SARS-CoV-2 from mainland Europe into Scotland. Nat Microbiol. 2021;6(1):112-22.

77. Bani Jolly, Mercy Rophina, Afra Shamnath, Mohammed Imran, Rahul C. Bhoyar, Mohit Kumar Divakar, Pallavali Roja Rani, Gyan Ranjan, Paras Sehgal, Pulala Chandrasekhar, S. Afsar, J. Vijaya Lakshmi, A. Surekha, Sridhar Sivasubbu VS. Genetic epidemiology of variants associated with immune escape from global SARS-CoV-2 genomes. bioRxiv [Internet]. 2020;(12.24.424332). Available from: https://www.biorxiv.org/content/10.1101/2020.12.24.424332v1.full 78. Challen R, Brooks-Pollock E, Read JM, Dyson L, Tsaneva-Atanasova K, Danon L. Risk of mortality in patients infected with SARS-CoV-2 variant of concern 202012/1: matched cohort study. BMJ [Internet]. 
2021;372:n579. Available from: http://www.ncbi.nlm.nih.gov/pubmed/33687922

79. Madhi SA, Baillie V, Cutland CL, Voysey M, Koen AL, Fairlie L, et al. Efficacy of the ChAdOx1 nCoV-19 Covid-19 Vaccine against the B.1.351 Variant. N Engl J Med [Internet]. 2021 Mar 16;NEJMoa2102214. Available from: http://www.nejm.org/doi/10.1056/NEJMoa2102214

80. Lagoumintzis, George, Christos T. Chasapis, Nikolaos Alexandris, Socrates Tzartos, Elias Eliopoulos, Konstantinos Farsalinos1 KP. COVID-19 and Cholinergic Anti-inflammatory Pathway: In silico Identification of an Interaction between $\alpha 7$ Nicotinic Acetylcholine Receptor and the Cryptic Epitopes of SARS-CoV and SARS-CoV-2 Spike Glycoproteins. bioRxiv [Internet]. 2020; Available from:

https://www.biorxiv.org/content/10.1101/2020.08.20.259747v1.full.pdf

81. Carfì A, Bernabei R, Landi F. Persistent Symptoms in Patients After Acute COVID-19. JAMA [Internet]. 2020 Aug 11;324(6):603. Available from: https://jamanetwork.com/journals/jama/fullarticle/2768351

82. Zhao Y, Shang Y, Song W, Li Q, Xie H, Xu Q, et al. Follow-up study of the pulmonary function and related physiological characteristics of COVID-19 survivors three months after recovery. EClinicalMedicine [Internet]. 2020 Aug;25:100463. Available from:

https://linkinghub.elsevier.com/retrieve/pii/S2589537020302078

83. Galván-Tejada CE, Herrera-García CF, Godina-González S, Villagrana-Bañuelos KE, Amaro JDDL, Herrera-García K, et al. Persistence of COVID-19 Symptoms after Recovery in Mexican Population. Int J Environ Res Public Health [Internet]. 2020 Dec 14;17(24):9367. Available from: https://www.mdpi.com/1660-4601/17/24/9367

84. Townsend L, Dyer AH, Jones K, Dunne J, Mooney A, Gaffney F, et al. Persistent fatigue following SARS-CoV-2 infection is common and independent of severity of initial infection. PLoS One. 2020;15(11 November).

85. Miller A. COVID -19: not just an acute illness. Trends Urol Men's Heal [Internet]. 2020 Nov 26;11(6):17-9. Available from: https://onlinelibrary.wiley.com/doi/10.1002/tre.776

86. Goërtz YMJ, Van Herck M, Delbressine JM, Vaes AW, Meys R, Machado FVC, et al. Persistent symptoms 3 months after a SARS-CoV-2 infection: the post-COVID-19 syndrome? ERJ Open Res [Internet]. 2020 Oct;6(4):00542-2020. Available from:

http://openres.ersjournals.com/lookup/doi/10.1183/23120541.00542-2020

87. Tenforde MW, Kim SS LC et al. Symptom Duration and Risk Factors for Delayed Return to Usual Health Among Outpatients with COVID-19 in a Multistate Health Care Systems Network - United States, March-June 2020 [Internet]. Available from: https://www.cdc.gov/mmwr/volumes/69/wr/mm6930e1.htm 88. NGAI JC, KO FW, NG SS, TO K-W, TONG M, HUI DS. The long-term impact of severe acute respiratory syndrome on pulmonary function, exercise capacity and health status. Respirology [Internet]. 2010 Apr;15(3):543-50. Available from: http://doi.wiley.com/10.1111/j.1440-1843.2010.01720.x

89. Lam MH-B. Mental Morbidities and Chronic Fatigue in Severe Acute Respiratory Syndrome Survivors. Arch Intern Med [Internet]. 2009 Dec 14;169(22):2142. Available from:

http://archinte.jamanetwork.com/article.aspx?doi=10.1001/archinternmed.2009.384 
